\title{
Glomerulonephritis in Two Patients with SpA Treated with TNF- $\alpha$ Blockers and a Review of the Literature
}

This article was published in the following Dove Press journal:

Biologics: Targets and Therapy

\author{
Constantina A Bounia (D) \\ Eftichia N Theodoropoulou' \\ Stamatic-Nick C Liossis (D) ${ }^{1,2}$ \\ 'Division of Rheumatology, Patras \\ University Hospital, Patras, Greece; \\ ${ }^{2}$ Department of Internal Medicine, \\ University of Patras Medical School, \\ Patras, Greece
}

\begin{abstract}
Renal failure or acute/chronic kidney damage may present as a clinical manifestation of rheumatic diseases. In addition treatment with DMARDs or biologic drugs may induce nephrotoxicity. In this case-based review, we present two patients with SpA under anti-TNF- $\alpha$ treatment admitted to our hospital because of renal failure and proteinuria. We review previously published yet isolated cases of TNF- $\alpha$ blocker-induced glomerular disease in patients with SpA. Renal manifestations are occasionally seen in patients with ankylosing spondylitis and psoriatic arthritis with IgA nephropathy being the most common of them. Anti-TNF- $\alpha$ agents although reportedly used for the treatment of glomerular nephropathy as a disease manifestation, they have been considered responsible for provoking renal damage in some cases. A diagnostic approach for patients with SpA treated with anti-TNF- $\alpha$ agents presenting with renal manifestations is proposed herein.
\end{abstract}

Keywords: spondylarthritides, glomerular disease, proteinuria, kidney biopsy, anti-TNFalpha agents

\section{Introduction}

The spondylarthritides (SpA) is an heterogenous group of inflammatory diseases sharing common features of axial and peripheral joint involvement. They include ankylosing spondylitis (axial SpA-AS), psoriatic arthritis (PsA), reactive arthritis and enteropathic arthritis. Anti-TNF- $\alpha$ agents are extensively used in the treatment of $\mathrm{SpA}$ in cases of non-responsiveness to non-steroid antiinflammatory drugs (NSAID) and disease modifying antirheumatic drugs (DMARD).

Patients with SpA may manifest with renal malfunction. It is of importance to differentiate if this renal involvement is a disease trait or a drug-related adverse effect, especially taking into account that NSAID and TNF- $\alpha$ blockers are used as treatment strategies.

In this case-based review, we report 2 patients with $\mathrm{SpA}$ admitted to our hospital because of renal malfunction, proteinuria and hematuria. Both patients were on treatment with TNF- $\alpha$ blockers. The literature was reviewed for similar case reports of anti-TNF- $\alpha$ induced glomerular disease in SpA (axial SpA-AS or PsA). Patients with rheumatoid arthritis (RA), psoriasis and inflammatory bowel disease (IBD), that revealed glomerular damage because of TNF- $\alpha$ inhibitors were not included in this review because they have been previously reported elsewhere. ${ }^{1-4}$ We also analyzed studies dealing with renal involvement as a clinical manifestation of $\mathrm{SpA}$, irrespectively of anti-TNF- $\alpha$ treatment.
Correspondence: Stamatic-Nick C Liossis Div. of Rheumatology, Patras University Hospital, GR 26500, Rion, Patras, Greece Tel +302613603693

Fax +302610993982

Email snliossis@med.upatras.gr
Biologics: Targets and Therapy 2021:15 6I-66 
Finally, we additionally propose a schematic diagnostic approach based upon our diagnostic thoughts; we also propose interventions to handle such patients with $\mathrm{SpA}$ and renal abnormalities.

\section{Case I}

The first patient was a 41-year-old man diagnosed with axial SpA-AS 9 years before admission. Six years before admission treatment with infliximab (INF) $5 \mathrm{mg} / \mathrm{kg}$ was initiated every 8 weeks. Three years before admission, because of a severe relapse of the disease with left hip and right knee arthritis, INF $(5 \mathrm{mg} / \mathrm{kg}$ ) was being administrated every 6 weeks for the following 1 year.

During the follow-up period blood and urine tests revealed proteinuria $(100 \mathrm{mg} / \mathrm{dL})$, microscopic hematuria (8-15 RBC phf) and a normal serum creatinine $(0.96 \mathrm{mg} /$ $\mathrm{dL})$. One year later the patient was admitted to our hospital due to respiratory tract infection and worsening of his renal function. On admission proteinuria, pyuria (leucocytes 10-12 phf) and microscopic hematuria (100 RBC phf) were also evident. The 24 -hour urinary protein excretion was $1748 \mathrm{mg}$.

The patient was treated with antibiotics and his infection resolved. Renal function further deteriorated $(\mathrm{Cr}$ : $4 \mathrm{mg} / \mathrm{dL}$ ) and a kidney biopsy was performed. The patient was treated with $1 \mathrm{~g}$ of methylprednisolone IV once, and was subsequently treated with methylprednisolone per os (prednisolone, $1 \mathrm{mg} / \mathrm{kg}$ ) with a gradual improvement of his renal function with a serum creatinine of $1.4 \mathrm{mg} / \mathrm{dL}$.

Kidney biopsy revealed thickening of the basement membranes, a multifocal inflammatory (lymphocytes and neutrophils) infiltrate of the interstitium, an intense interstitial granular IgA fixation and a moderate interstitial fixation of $\mathrm{C} 3$. These findings were compatible with a pathological diagnosis of IgA nephropathy. As a result, INF was discontinued and steroid dosages were quickly tapered to $10 \mathrm{mg}$ methylprednisolone/day.

\section{Case 2}

Our second patient was a 50-year-old man with a history of hypertension and Graves' disease, who was diagnosed with PsA 3.5 years before admission. The patient was initially treated with cyclosporine $2.5 \mathrm{mg} / \mathrm{kg}$; however, over the last 6 months before admission he was treated with adalimumab (ADA) 40mg every other week plus methotrexate $10 \mathrm{mg}$ per week.

Because of anemia and gradual deterioration of his renal function over the past 3 months before admission, he was admitted to the Nephrology Clinic of our hospital.
Anemia (Ht: $31.7 \%$ ) and renal dysfunction (Cr: $2 \mathrm{mg} / \mathrm{dL}$ ) were found upon admission. Apart from significant proteinuria $(2.5 \mathrm{~g} / 24 \mathrm{~h})$, urinalysis revealed 6-8 leucocytes phf, 35-40 RBC phf and red cell casts. In addition, antinuclear antibodies were negative, whereas a p-ANCA titre was reportedly $1 / 80$. A kidney biopsy was performed and the pathological findings were fully compatible with pauciimmune crescentic glomerulonephritis. More specifically, glomerular crescents, glomerular sclerosis, interstitial inflammation and a slight only deposition of $\operatorname{IgG}$ were seen.

Following the discontinuation of ADA and methotrexate, the patient was treated with 3 IV pulses of $1 \mathrm{~g}$ of methylprednisolone each followed by high dosages of orally administered steroids (prednisolone, $1 \mathrm{mg} / \mathrm{kg}$ ). Monthly pulses of $1 \mathrm{~g}$ IV cyclophosphamide (CYC) were also administered over the following 6 months. Kidney function significantly improved at 6 months of treatment (U: $61 \mathrm{mg} / \mathrm{dL}, C r: 1,2 \mathrm{mg} / \mathrm{dL}$ ) and hematuria resolved (RBC: 0-2phf). However, because of resistant proteinuria $(>2 \mathrm{~g} / 24 \mathrm{~h}), \mathrm{B}$ cell depletion treatment was added with 4 weekly pulses of rituximab (RTX) $375 \mathrm{mg} / \mathrm{m}^{2}$. Proteinuria was gradually reduced to $700 \mathrm{mg} /$ day 6 months afterwards.

\section{Discussion}

We approached the two patients described above once they were admitted in our hospital. Biologics were discontinued upon verifying renal dysfunction, proteinuria and hematuria in both patients. Kidney biopsy was performed and treatment with steroid infusions was administrated according to biopsy results. Immunosuppressive agents were added in cases of worsening and non- responsiveness of patients to the initial treatment.

Therefore, despite keeping in mind that IgA nephropathy could be a concurrent manifestation of axial SpAAS, we stopped the treatment with biological agent in the first case. Kidney biopsy was performed to define the type of renal involvement. We followed the same strategy in the second case of PsA as far as the diagnosis and treatment are concerned. We chose high doses of steroids and we added (whenever necessary) immunosuppressive agents to treat glomerulonephritis.

\section{Anti-TNF- $\alpha$ Agents-Induced Glomerular Disease}

Autoimmune manifestations triggered by TNF- $\alpha$ blockers are rare events. A retrospective analysis of such manifestations 
Table I Case Reports of Anti-TNF- $\alpha$-Induced Glomerular Disease in SpA

\begin{tabular}{|c|c|c|c|c|c|}
\hline Patient & Disease & Anti-TNF $\alpha^{* *}$ & Renal Abnormalities & Kidney Biopsy & Ref. \\
\hline đ 27 & AS & GLM/ADA & $\uparrow$ u-Prot, RBC,casts & $\lg A \mathrm{mGN}$ and $M G N$ & [7] \\
\hline+60 ys & AS & ETN & RBC,WBC, casts, $\uparrow$ u-Prot (10 g/day) & Membranous GN & [8] \\
\hline 061 & AS & ETN & $\mathrm{RBC}, \uparrow \mathrm{s}-\mathrm{Cr}, \uparrow \mathrm{u}-$ Prot & $\lg \mathrm{A}$ and $\mathrm{C} 3 \mathrm{mGN}(\mathrm{HSP})$ & [9] \\
\hline 37 ys & AS & INF & $\mathrm{RBC}, \uparrow \mathrm{s}-\mathrm{Cr}, \uparrow \mathrm{u}-\operatorname{Prot}(\mathrm{I} .7 \mathrm{~g} /$ day $)$ & $\lg A$ MGN & {$[10]$} \\
\hline 42 ys & AS & ADA & $\uparrow \mathrm{s}-\mathrm{Cr}$ & Granulomatous interstitial nephritis & {$[\mathrm{II}]$} \\
\hline$\uparrow \mathbf{4 0} \mathrm{ys}$ & AS & ETN/INF & $\uparrow$ u-Prot, RBC & FSGS & [12] \\
\hline$\$ 47$ ys & AS & ADA & $\mathrm{RBC}, \uparrow \mathrm{s}-\mathrm{Cr}, \uparrow \mathrm{u}-\operatorname{Prot}(2.6 \mathrm{~g} /$ day $)$ & NCGN & [13] \\
\hline $57 \mathrm{ys}$ & PsA & ETN & $\uparrow \mathrm{s}-\mathrm{Cr}, \uparrow \mathrm{u}-\mathrm{Prot}, \mathrm{RBC}$ & - & [14] \\
\hline $29 \mathrm{ys}$ & PsA & ADA & $\uparrow \mathrm{u}-$ Prot & Mesangial GN & [6] \\
\hline
\end{tabular}

Note: **Anti TNF administration refers to one, or two agents with the second one presented being the most recent.

Abbreviations: ETN, etanercept; ADA, adalimumab; INF, infliximab; GLM, golimumab; RBC, red blood cells; WBC, white blood cells; $\uparrow$ S-Cr, increased serum creatinine; $\uparrow$ U-Prot, increased proteinuria; MGN, membranous glomerulonephritis; NCGN, necrotizing crescentic glomerulonephritis; mGN, mesangial glomerulonephritis; HSP, Henoch-Shönlein purpura; FSGS, focal segmental glomerulosclerosis.

secondary to TNF- $\alpha$ inhibition was performed. ${ }^{5}$ A total of 233 patients with RA, axial SpA-AS, PsA and other rheumatic diseases were included. The anti-TNF $\alpha$ agents that were administered, [INF, etanercept (ETN), ADA)] could induce various autoimmune manifestations in all groups of patients. Seven patients with axial SpA-AS and 6 patients with PsA were afflicted. Most anti-TNF- $\alpha$ induced events were clearly seen in patients with RA. Three axial SpA-AS and 3 PsA patients displayed internal organ vasculitis. Kidney involvement was reported in 15/233 patients. Lupus-like disease was seen in 2 axial SpA-AS and 2 PsA patients, while lupus-like nephropathy was diagnosed in $5 / 233$ patients. The exact number of axial SpA-AS and PsA patients that had kidney vasculitis or lupus-like nephropathy is not clear.

A study by Piga et $\mathrm{al}^{6}$ aimed to describe the features of biologics-induced autoimmune renal disorders. The above autoimmune disorders were categorized according to clinical manifestations and renal pathology in 3 groups: 1) glomerulonephritis associated with systemic vasculitis (GNSV), 2) glomerulonephritis in lupus-like syndrome (GNLS), and 3) isolated autoimmune renal disorders (IARD). Twenty two out of 29 patients were diagnosed with RA, 5/29 with axial SpA-AS and 2/29 with PsA.

Apart from the above 2 retrospective studies, there are scarce case reports in the literature that have reported glomerular disease as an adverse event of anti-TNF $\alpha$ treated SpA. The case reported by Davide et al is of special interest; ${ }^{7}$ it refers to a young man with axial SpA-AS that was treated initially with golimumab for 5 years and then switched to ADA because of active sacroiliitis. The patient displayed worsening proteinuria and the kidney biopsy performed revealed both IgA nephropathy with minimal mesangial deposits and membranous nephropathy. Renal abnormalities and kidney biopsy results are depicted in Table 1 according to underlying disease and to the antiTNF- $\alpha$ agent implicated. ${ }^{8-14}$

\section{Renal Involvement in the SpA}

Axial SpA-AS can be accompanied by extraarticular manifestations primarily of the cardiovascular and respiratory system. Renal disease is exceptionally rare. ${ }^{15}$ Secondary renal amyloidosis is the most common cause of renal involvement in axial SpA-AS (62\%) followed by IgA nephropathy $(30 \%)$, mesangioproliferative glomerulonephritis $(5 \%)$ as well as, rarely, membranous nephropathy (1\%), focal segmental glomerulosclerosis $(1 \%)$ and focal proliferative glomerulonephritis (1\%). Treatmentassociated nephrotoxicity may result from NSAID or DMARD.

The incidence of renal abnormalities like glomerulonephritis, IgA immune-complex deposition, renal amyloid deposition, microscopic hematuria, proteinuria and impaired renal function have been reported in a range from 10 to $35 \%$ in patients with axial SpA-AS. ${ }^{16}$ Subclinical amyloidosis although rare is more prevalent in older patients with chronic disease. Prognosis cannot be defined based upon positive findings of AA amyloidosis in fat aspiration from asymptomatic axial SpA-AS patients.

In another study the authors retrospectively reviewed 28 cases with renal involvement out of 210 cases of patients with axial SpA-AS seen over a 27 year period. ${ }^{17}$ These patients displayed one or more of the following: a) macroscopic hematuria $(n=4), b)$ microscopic hematuria $(\mathrm{n}=8)$, c) proteinuria $(\mathrm{n}=15)$, d) nephrotic syndrome $(n=6)$ and e) decreased renal function $(n=13)$. Renal amyloidosis and nephrolithiasis were seen in 8 patients and 
IgA nephropathy in 3 patients. Therefore, the authors conclude that renal involvement is not negligible in patients with axial SpA-AS and suggest a regular followup of their renal function.

Levy et al comparatively evaluated for the development of renal abnormalities in persons with axial SpA-AS and in the general population by analyzing databases with medical files over a 10 -year period. ${ }^{18}$ Patients with axial SpA-AS were 8616 (4836 men, 3780 women with a median age of 42.5 years old when first diagnosis of the disease was made). Subjects with previously diagnosed renal disease were excluded from this analysis. Acute kidney injury and chronic renal failure were the most common diagnoses while renal amyloidosis and hypertensive kidney disease were the least frequent. The prevalence of renal complications was approximately 3.4\% among men and $2.1 \%$ among women with axial SpA-AS, in comparison to the general population that was $1.9 \%$ for men and $1.5 \%$ for women, respectively. It was readily evident that the younger the patients at diagnosis, the higher the danger of developing renal impairment. However it should be noticed that the definitions of "renal disease" are not clearly stated in this retrospective study.

Champtiaux et al studied 32 patients with SpA-associated IgA nephropathy. Patients with axial SpA-AS $(n=20)$, undifferentiated SpA ( $n=7)$, PsA $(n=3)$ and IBD-associated SpA $(n=2)$ were included. ${ }^{19}$ In the majority, ie in $23 / 32$ patients, the diagnosis of rheumatic disease preceded that of renal disease, whereas in $5 / 23$ patients the rheumatic and the renal disease manifested almost simultaneously, within 1 year. Kidney disease was mainly asymptomatic with accidentally found proteinuria and/or microhematuria $(n=18)$. Specimens from 27 kidney biopsies displayed sclerotic glomeruli (12\%), cellular or fibrocellular crescents $(n=9 / 27)$ and thrombotic microangiopathy $(\mathrm{n}=1 / 27)$. Arterial intimal thickening was a common finding ( $\mathrm{n}=14 / 27)$, as was interstitial inflammation, at a percentage of $>10 \%$ of the cortical area $(n=5 / 27)$. Renal prognosis was poor, with rapidly progressing renal dysfunction ending up in chronic renal failure, $\mathrm{CKD}$ stage 4 or 5. Adding anti-TNF- $\alpha$ to the treatment regime could not prevent renal function worsening.

Sang-Hoon Lee et al analyzed 681 patients with axial SpA-AS, including 547 men and 134 women; ${ }^{20} 81 \%$ of the patients were HLA-B27 positive and abnormal urinalysis findings were detected in $8 \%$ (proteinuria, hematuria or both). Because of significant proteinuria ( $>1 \mathrm{~g} /$ day) 6 patients underwent renal biopsy. Pathology revealed IgA nephropathy $(\mathrm{n}=2)$, amyloidosis $(\mathrm{n}=1)$, and nonspecific glomerulo-nephropathy $(\mathrm{n}=3)$. TNF $\alpha$ blocking treatment resolved proteinuria in patients with amyloidosis but not in patients with IgA nephropathy. Patients with normal serum creatinine levels in this small group also had a better response to anti-TNF $\alpha$ treatment in comparison to patients with abnormal serum creatinine levels.

The ASAA-COMOSPA study by Couderc et al assessed the prevalence of renal complications in in a quite large number of SpA patients. ${ }^{21}$ Centers from 22 countries from 4 continents were participating in this trial. The MDRD equation for the calculation of eGFR was employed to assess for a potential renal function decline. Of the 3984 patients recruited in the study, 2098 were evaluated for their eGFR. Most were male $(n=1332)$ with a mean age \pm SD of $45 \pm 13$ years and a mean SpA duration of about 9 years. In addition, 1126/1332 were HLA-B27 positive. Sacroiliitis was depicted on radiographs (1315/ 2098) and on magnetic resonance imaging (558/2098) of patients with SpA. Patients of mean age \pm SD of $53.6 \pm$ 14.6 years $(153 / 2098)$ were reported with an eGFR < $60 \mathrm{~mL} / \mathrm{min} / 1.73 \mathrm{~m}^{2}$ and the rest of them $(1945 / 2098)$ aged $44.6 \pm 13.3$ years with an eGFR $>60 \mathrm{~mL} / \mathrm{min} /$ $1.73 \mathrm{~m}^{2}$. After a direct comparison between the group of patients with eGFR $>60 \mathrm{~mL} / \mathrm{min} / 1.73 \mathrm{~m}^{2}$ and the group with an eGFR $<60 \mathrm{~mL} / \mathrm{min} / 1.73 \mathrm{~m}^{2}$, the authors reported correlations of renal dysfunction with certain parameters. More specifically, renal impairment was found to be positively correlated with age $(\mathrm{p}<0.001)$, with HLA-B27 positivity ( $\mathrm{p}=0.003$ ), with disease activity scores (BASDAI: $\mathrm{p}<0.001$ and ASDAS-CRP: $\mathrm{p}=0.001$ ) and with markers of inflammation $(p<0.001)$. In contrast, it was not associated with cardiovascular (CV) risk factors, with disease severity or duration, or with NSAID intake in patients with SpA. Renal impairment was also not correlated with treatment with DMARDs or with anti-TNF- $\alpha$ agents. Limitations of the study was the lack of data collection for hematuria, pyuria or proteinuria and the difficulty of collecting urine samples from patients from different counties under the same conditions.

Few case reports suggest the potential role of TNF- $\alpha$ inhibitors in improving AA amyloidosis ${ }^{10}$. Axial SpA-AS -related secondary amyloidosis responded well to treatment with etanercept. ${ }^{22}$ In contrast, other case reports are not displaying satisfactory results with anti-TNF $\alpha$ drugs used in treating nephropathy in $\mathrm{SpA}^{23}$.

In conclusion, after having been dealing with the 2 patients with SpA on anti TNF- $\alpha$ and renal derangement 


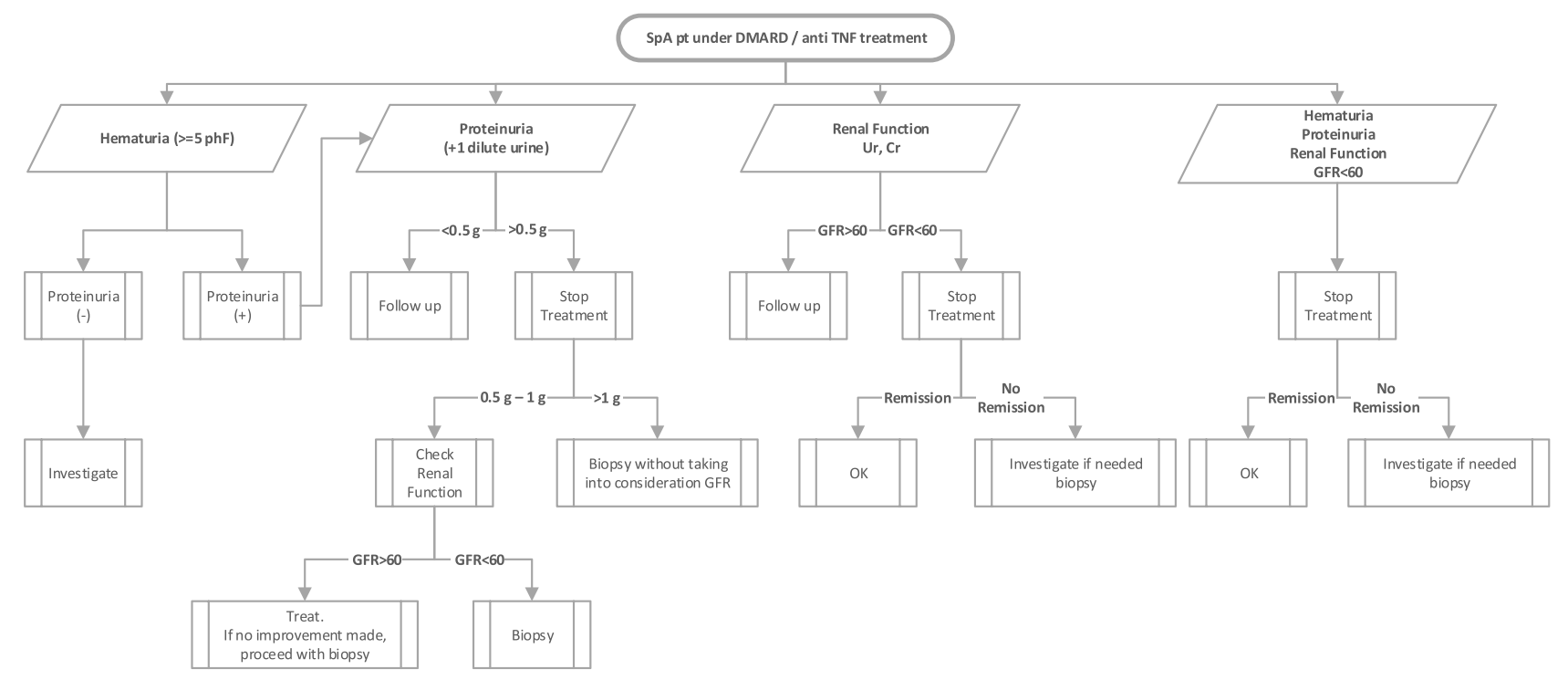

Figure I A proposed decision tree on the approach of the patient with SpA and renal involvement.

we reviewed the literature for similar cases. It is ascertained that renal and more particularly glomerular disease as in our two patients may present in patients with $\mathrm{SpA}$ receiving TNF-alpha blockers,not only with axial SpA-AS but also with PsA.

\section{Conclusions}

Patients with SpA such as axial SpA-AS and PsA can manifest with renal disease, which is usually considered as a manifestation in their clinical spectrum. IgA nephropathy is usually reported in the pathological findings of SpA patients' kidney biopsies. However we should keep in mind that renal and glomerular disease in particular may appear following initiation of anti-TNF- $\alpha$ agents. Nephropathy, either as a disease manifestation or as a TNF- $\alpha$ blocker induced adverse event can be rather progressive and of poor prognosis.

That is why we propose a diagnostic approach for SpA patients treated with anti TNF- $\alpha$ agents that present with renal dysfunction and/or abnormal urinalysis (proteinuria, hematuria, pyuria, red cell casts and active urinary sediment). Our approach is depicted in the decision tree of Figure 1.

\section{Disclosure}

The authors report no conflicts of interest in this work.

\section{References}

1. Stokes MB, Foster K, Markowitz GS, et al. Development of glomerulonephritis during anti-TNF-alpha; therapy for rheumatoid arthritis. Nephrol Dial Transplant. 2005;20:1400-1406. doi:10.1093/ndt/gfh832
2. Ayaash A, Maan D, Kapetanos A, Bunker M, Wasko MC, Clark B Significance of crescentic glomeruli in acute kidney injury with rheumatoid arthritis. Case Reports Nephrol Dial. 2019;9:42-48. doi:10.1159/000500105

3. Premužić V, Padjen I, Cerovec M, Ćorić M, Jelaković B, Anić B. The association of TNF-alpha inhibitors and development of IgA nephropathy in patients with rheumatoid arthritis and diabetes. Case Rep Nephrol. 2020.

4. Morgane V, Jean-Charles C, Nicolas M, et al. Renal sarcoid-like granulomatosis during anti-TNF therapy. Kidney Int. 2014;86:215. doi:10.1038/ki.2013.452

5. Ramos-Casals M, Brito-Zerón P, Soto MJ, Cuadrado MJ, Khamashta MA. Autoimmune diseases induced by TNF-targeted therapies. Best Pract Res Clin Rheumatol. 2008;22:847-861. doi:10. 1016/j.berh.2008.09.008

6. Piga M, Chessa E, Ibba V, et al. Biologics-induced autoimmune renal disorders in chronic inflammatory rheumatic diseases: systematic literature review and analysis of a monocentric cohort. Autoimmun Rev. 2014;13:873-879. doi:10.1016/j.autrev.2014.05.005

7. Davide D, Marta P, Antonella B, et al. Double glomerulonephritis in a patient with ankylosing spondylitis treated with biologic agent: extrarticolar involvement or anti-tumor necrosis factor alpha injury? A case-based review. Clin Med Insights Case Rep. 2020;13. doi:10.1177/1179547620974672

8. Rolle AS, Zimmermann B, Poon SH. Etanercept-induced henochschönlein purpura in a patient with ankylosing spondylitis. J Clin Rheumatol. 2013;19:90-93. doi:10.1097/RHU.0b013e3182863027

9. Kaushik P, Rahmani M, Ellison W. Membranous glomerulonephritis with the use of etanercept in ankylosing spondylitis. Ann Pharmacother. 2011;45:1585. doi:10.1345/aph.1Q492

10. Jacquet A, Francois H, Frangie C, et al. IgA nephropathy associated with ankylosing spondylitis is not controlled by infliximab therapy. Nephrol Dial Transplant. 2009;24:3540-3542. doi:10.1093/ndt/gfp314

11. Korsten P, Sweiss NJ, Nagorsnik U, et al. Drug-induced granulomatous interstitial nephritis in a patient with ankylosing spondylitis during therapy with adalimumab. Am J Kidney Dis. 2010;56:e17e21. doi:10.1053/j.ajkd.2010.08.019

12. Yarkan Tuğsal H, Zengin B, Kenar G, et al. Infliximab-associated focal segmental glomerulosclerosis in a patient with ankylosing spondylitis. Rheumatol Int. 2019;39:561-567. doi:10.1007/s00296019-04241-8 
13. Tosovský M, Bradna P, Laco J, Podhola M, Soukup T, Brozík J. Case 1-2012: ANCA associated glomerulonephritis in combination with IgG4-positive mediastinal mass in a patient with ankylosing spondylitis treated with TNF alpha inhibitors. Acta Medica (Hradec Kralove). 2012;55:42-46. doi:10.14712/18059694.2015.74

14. Lee A, Kasama R, Evangelisto A, Elfenbein B, Falasca G. HenochSchönlein purpura after etanercept therapy for psoriasis. $J$ Clin Rheumatol. 2006;12:249-251. doi:10.1097/01.rhu.0000239901.34561.5e

15. Strobel ES, Fritschka E. Renal diseases in ankylosing spondylitis: review of the literature illustrated by case reports. Clin Rheumatol. 1998;17:524-530. doi:10.1007/BF01451293

16. El Maghraoui A. Extra-articular manifestations of ankylosing spondylitis: prevalence, characteristics and therapeutic implications. Eur J Intern Med. 2011;22:554-560. doi:10.1016/j.ejim.2011.06.006

17. Ben Taarit C, Ajlani H, Ben Moussa F, Ben Abdallah T, Ben Maïz H, Khedher A. Renal involvement in ankylosing spondylitis: concerning 210 cases. Rev Med Interne. 2005;26:966-969. doi:10.1016/j. revmed.2005.07.017

18. Levy AR, Szabo SM, Rao SR, Cifaldi M, Maksymowych WP. Estimating the occurrence of renal complications among persons with ankylosing spondylitis. Arthritis Care Res. 2014;66:440-445. doi:10.1002/acr.22176
19. Champtiaux N, Lioté F, El Karoui K, et al. Spondyloarthritisassociated IgA nephropathy. Kidney Int Rep. 2020;5:813-820. doi:10.1016/j.ekir.2020.03.012

20. Lim SJ, Lee EJ, Chung SW, et al. Renal involvement in ankylosing spondylitis: prevalence, pathology, response to TNF-a blocker. Rheumatol Int. 2013;33:1689-1692. doi:10.1007/s00296-012-2624-9

21. Couderc M, Pereira B, Molto A, Tiple A, Soubrier M, Dougados M. The prevalence of renal impairment in patients with spondyloarthritis: results from the international ASAS-COMOSPA study. J Rheumatol. 2018;45:795-801. doi:10.3899/jrheum.170133

22. Kobak S, Oksel F, Kabasakal Y, Doganavsargil E. Ankylosing spondylitis-related secondary amyloidosis responded well to etanercept: a report of three patients. Clin Rheumatol. 2007;26:2191-2194. doi:10.1007/s10067-007-0679-x

23. Sakellariou GT, Vounotrypidis P, Berberidis C. Infliximab treatment in two patients with psoriatic arthritis and secondary IgA nephropathy. Clin Rheumatol. 2007;26:1132-1133. doi:10.1007/ s10067-006-0422-z

\section{Publish your work in this journal}

Biologics: Targets and Therapy is an international, peer-reviewed journal focusing on the patho-physiological rationale for and clinical application of Biologic agents in the management of autoimmune diseases, cancers or other pathologies where a molecular target can be identified. This journal is indexed on PubMed Central, CAS, EMBase,
Scopus and the Elsevier Bibliographic databases. The manuscript management system is completely online and includes a very quick and fair peer-review system, which is all easy to use. Visit http://www.dovepress.com/testimonials.php to read real quotes from published authors. 